\title{
A Quantitative Assessment of the Amount of Prion Diverted to Category 1 Materials and Wastewater During Processing
}

\author{
Amie Adkin, ${ }^{1, *}$ Neil Donaldson, ${ }^{1}$ and Louise Kelly ${ }^{1,2}$
}

\begin{abstract}
In this article the development and parameterization of a quantitative assessment is described that estimates the amount of TSE infectivity that is present in a whole animal carcass (bovine spongiform encephalopathy [BSE] for cattle and classical/atypical scrapie for sheep and lambs) and the amounts that subsequently fall to the floor during processing at facilities that handle specified risk material (SRM). BSE in cattle was found to contain the most oral doses, with a mean of $9864 \mathrm{BO} \mathrm{ID}_{50} \mathrm{~S}(310,38840)$ in a whole carcass compared to a mean of $1851 \mathrm{OO} \mathrm{ID}_{50} \mathrm{~s}(600,4070)$ and $614 \mathrm{OO} \mathrm{ID}_{50} \mathrm{~s}(155,1509)$ for a sheep infected with classical and atypical scrapie, respectively. Lambs contained the least infectivity with a mean of $251 \mathrm{OO} \operatorname{ID}_{50} \mathrm{~s}(83,548)$ for classical scrapie and $1 \mathrm{OO} \operatorname{ID}_{50} \mathrm{~s}(0.2,2)$ for atypical scrapie. The highest amounts of infectivity falling to the floor and entering the drains from slaughtering a whole carcass at SRM facilities were found to be from cattle infected with BSE at rendering and large incineration facilities with 7.4 $\mathrm{BO} \mathrm{ID}_{50} \mathrm{~s}(0.1,29)$, intermediate plants and small incinerators with a mean of $4.5 \mathrm{BO} \mathrm{ID}_{50} \mathrm{~s}(0.1,18)$, and collection centers, $3.6 \mathrm{BO} \mathrm{ID}_{50} \mathrm{~s}(0.1$, 14). The lowest amounts entering drains are from lambs infected with classical and atypical scrapie at intermediate plants and atypical scrapie at collection centers with a mean of $3 \times$ $10^{-7}$ OO ID ID $_{50}\left(2 \times 10^{-8}, 1 \times 10^{-6}\right)$ per carcass. The results of this model provide key inputs for the model in the companion paper published here.
\end{abstract}

KEY WORDS: Abattoir; bovine spongiform encephalopathy; QRA; scrapie; TSE

\section{INTRODUCTION}

The approved means by which animal byproducts can be disposed of in the United Kingdom are laid down in the European Commission (EC) Animal By-Product (ABP) Regulation 1774/2002. This regulation was introduced to minimize the risk to human and animal health arising from by-product

${ }^{1}$ Epidemiology, Surveillance and Risk Group, Animal Health and Veterinary Laboratories Agency, Woodham Lane, Weybridge, KT15 3NB, UK.

${ }^{2}$ Department of Mathematics and Statistics, University of Strathclyde, Richmond Street, Glasgow, G1 1XH, UK.

*Address correspondence to Amie Adkin, Epidemiology, Surveillance and Risk Group, Animal Health and Veterinary Laboratories Agency, Woodham Lane, Weybridge, KT15 3NB, UK; amie.adkin@ahvla.gsi.gov.uk. disposal, and includes the specific risks arising from potentially transmissible spongiform encephalopathy (TSE) infected livestock. The ABP Regulation recognizes that risks posed by animal by-products are dependent on their origin and creates a framework for further handling, use, and/or disposal using a tiered strategy according to category of risk. Category 1 is highest risk waste, and includes TSE confirmed/suspected animals, TSE specified risk material (SRM), zoo, and experimental animal carcasses. Such materials must be sent for disposal by incineration or rendering followed by incineration. Category 2 material is also high risk, but is not associated with TSE risk. Fallen stock (animals that have died on farm) and slaughter material considered unfit due to the likely presence of communicable disease or residues of drugs/medicines are examples of this 
category. There is limited reuse of these materials, for example, recovery of hides and restricted flesh production for hounds at collection centers (knackers yards), and a large proportion is disposed of by rendering and/or incineration. Fallen stock will contain some SRM where the dead stocks are cattle and sheep. If this SRM is not removed before disposal of the carcass, then the whole carcass must be disposed of as Category 1 material. The third and final category is classified as lower risk material and is permitted for wider reuse and disposal options. Examples of Category 3 materials range from meat that is fit for human consumption but no longer intended to be consumed, to hides, skins, feathers, and feet derived from such animals.

Therefore, with regards to TSEs the facilities handling the highest risk tissues or SRM include abattoirs where healthy animals are slaughtered and the SRM are removed and placed in Category 1 bins, those facilities handling entire fallen stock such as bulking up centers (intermediate plants), flesh collection centers, renderers and incinerators, and those facilities that dispose of parts of the carcass such as SRM by rendering and incineration. Testing for prions may occur at intermediate plants, renderers, and incineration sites, but not at flesh collection centers.

During processing at these facilities small amounts of potentially infectious material are lost to the floor either directly or due to the washing down of other surfaces. This material is then filtered, by legal requirement, through a 6-mm trap as wastewater before any treatment and direct spreading to land. Central to risk assessments investigating the application of effluents from facilities handling high-risk materials is the estimation of the total amount of potentially infectious material entering a process, the proportion that falls to the floor, and the remaining proportion that survives processing and could subsequently be applied to land where livestock have access. Due to the predilection of the TSE agent for certain tissues, primarily the central nervous system (CNS), such risk assessments need to investigate the fate of individual tissue types within each of the processing environments.

This article describes the quantification of the total amount of infectivity present in individual infected cattle, sheep, and lamb carcasses for the TSE agents bovine spongiform encephalopathy (BSE), ovine scrapie, and ovine atypical scrapie. In addition, the amounts of infectivity lost to the floor and diverted to drains, per infected carcass, are estimated. These estimates are used in the subsequent paper that investigates the numbers of infected animals processed at different plants and the production and application of wastewater to estimate the prion risk associated with pasture fertilized by wastewater.

\section{METHODS}

Quantification of the amount of infectivity was undertaken using a probabilistic model with random variables and uncertain parameters described by appropriate probability distributions. The model was implemented in @Risk ( ${ }^{\circ}$ Palisade) Version 4.5, an add-on package within Microsoft Excel ( ${ }^{\circ}$ Microsoft). The results presented follow the standard form of the arithmetic mean and the 5th and 95th percentile values. Accordingly, the latter represent the range of values for which we are $90 \%$ certain that the true value lies between. The variables and parameters are described in each of the subsequent sections, with a summary provided in Table I. In a number of important areas published data were not available. Therefore, discussions were held with those experts conducting relevant laboratory experiments and veterinary officials who routinely visit and inspect licensed premises in Britain. In addition to these discussions, specific visits were performed to the different types of facilities to observe animal slaughter and fallen stock processes.

\subsection{Model Overview}

The amount of infectivity of type $i, i \in\{b s e, s c$, at $\}$, present in tissue type $t, t=1$ to 14 , listed in Table I of an infected carcass of animal type $a, a$ $\in\{C, S, l\}$, is defined as $I_{-}$carcass $_{a, i}$. Here bse, sc, and at represent BSE, classical scrapie, and atypical scrapie, respectively, and $C, S$, and $l$ represent cattle, sheep, and lambs respectively. I_carcass $a_{a . i}$ is estimated as the product of the amount of infectious materials in grams, $N_{-}$carcass $_{a, t}$ and the titre of infectivity(Oral $\left.\mathrm{ID}_{50} / \mathrm{g}\right)$, Infectivity $a, i, t$.

Upon entry into a processing facility, much of the highly infectious material will be targeted and collected as Category 1 materials for disposal. However, during processing, some will be released and fall to floor or be washed down from equipment. This material will then arrive at the 6-mm trap and, potentially, the facility drains, as shown in Fig. 1. The amount of infectivity passing through the trap, and thus into the drains, I_drain $a, i, k$, (Oral $\mathrm{ID}_{50}$ per carcass) is estimated for each animal group, each disease, and each SRM processing facility. For abattoirs, intermediate 


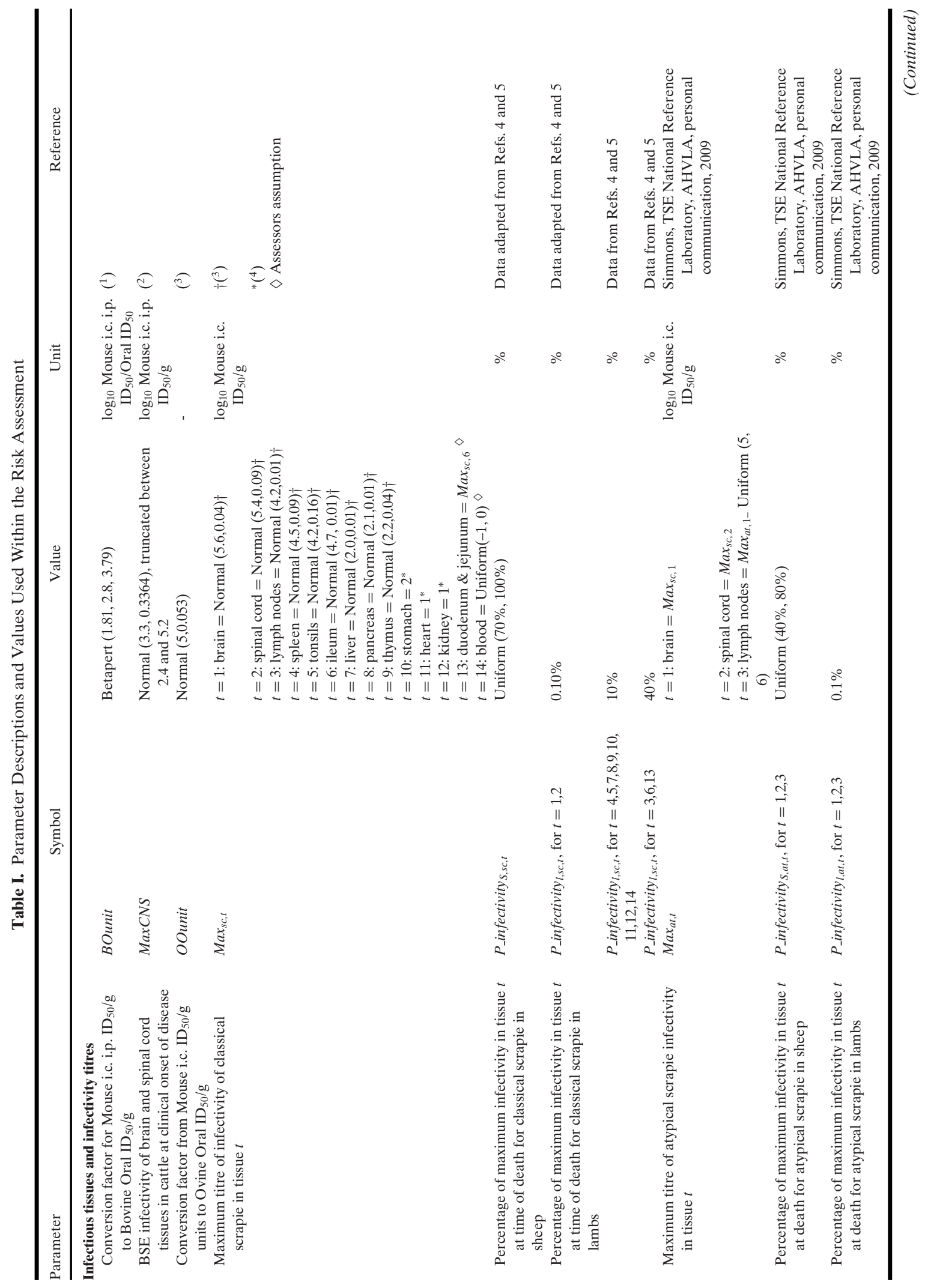




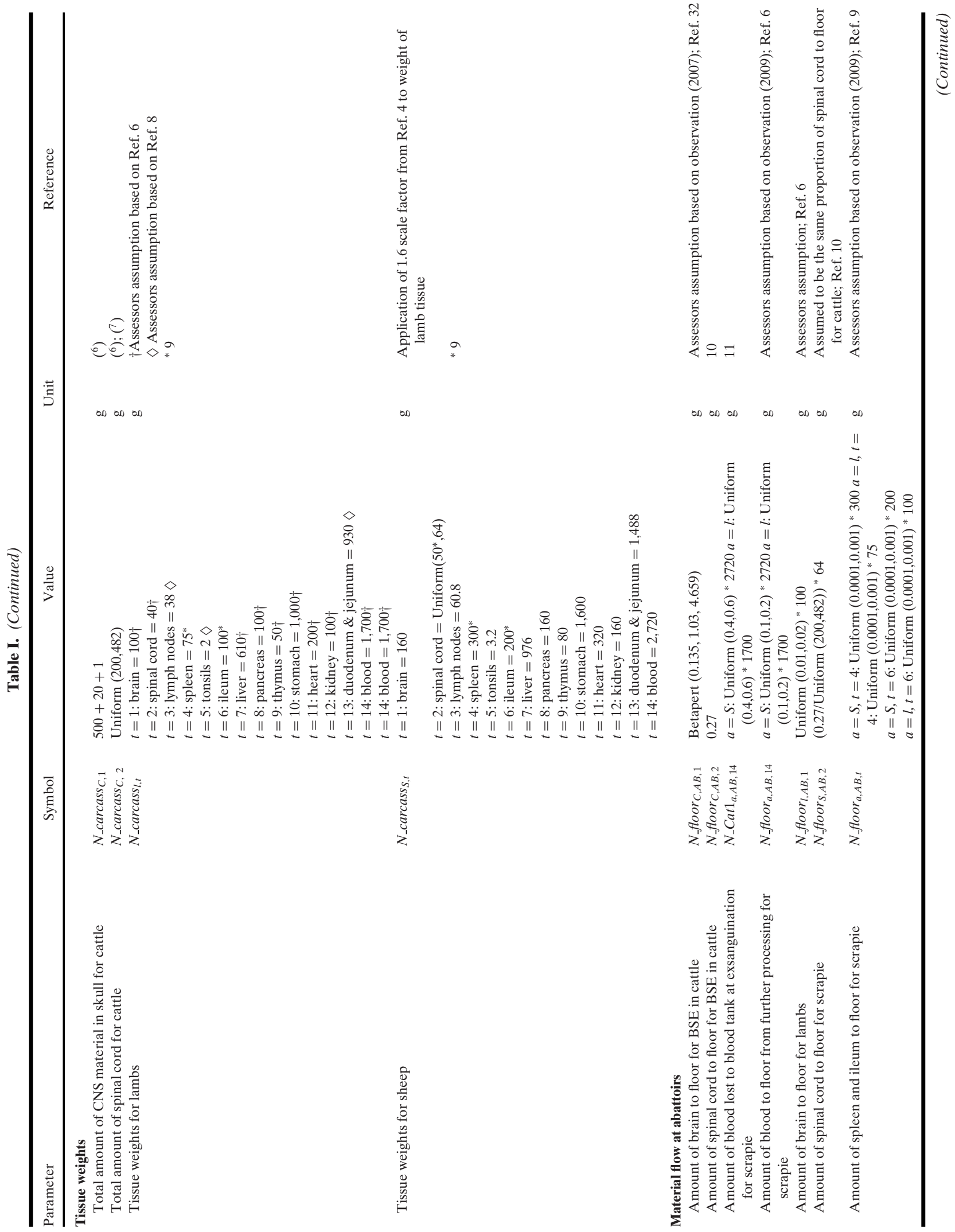


Amount of Prions from Processed Livestock Carcasses

5

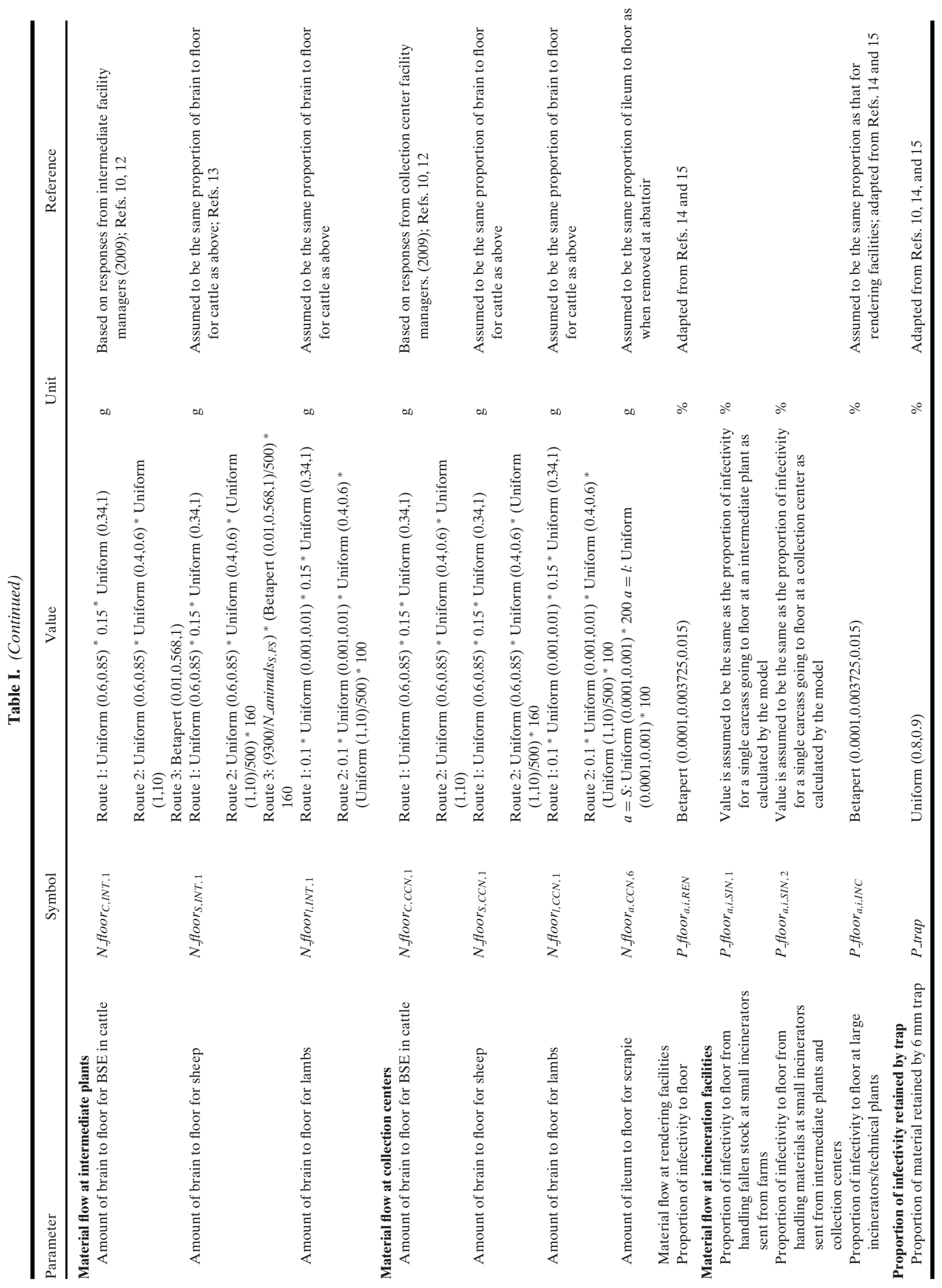


and collection centers, denoted by $k \in\{A B, I N T$, $C C N\}$, this amount $i$ is given by Equation (1):

$$
\begin{aligned}
I_{\_} \text {drain }_{a, i, k}= & \sum_{t} N_{-} \text {floor }_{a, k, t}{ }^{*} \text { Infectivity }_{a, i, t}{ }^{*} \\
& \times\left(1-P_{\text {trap }}\right),
\end{aligned}
$$

where $N_{-}$floor $_{a, k, t}$ is the amount in grams of infectious tissue type $t$ that falls to the floor per carcass at each facility type, and the percentage of infectivity retained by the trap is denoted $P_{\text {_trap }}$.

The amount of infectivity disposed of as Category 1 waste from each facility type (Oral ID 50 per carcass), is estimated by calculating the amount of infectivity remaining (as a fraction of that fallen to the floor) and adding the material retained by the trap, as shown in Equation (2):

$$
\begin{aligned}
I_{-} \text {Cat1 }_{a, i, k}= & \sum_{t}\left(N_{-} \text {carcass }_{a, t}-N_{-} \text {floor }_{a, k, t}\right. \\
& \left.+N_{-} \text {trap }_{a, k, t}\right)^{*} \text { Infectivity }_{a, i, t},
\end{aligned}
$$

where

$$
N_{-} \text {trap }_{a, k, t}=N_{-} \text {floor }_{a, k, t}{ }^{*} P_{\_} \text {trap }
$$

denotes the amount of infectivity (grams) that is retained in the trap and subsequently placed in the Category 1 bins for disposal. For rendering $(R E N)$ and incineration $(S I N)$, estimates for the amount of material that falls to the floor were not available from the literature or from visits made to facilities. However, estimates have been provided in previous risk assessments $^{(14-16)}$ for the proportion of infectivity from input material derived from an infected carcass that could enter the drainage system. The amount of infectivity passing through the drains at rendering and large incinerators accepting whole fallen stock (that is, only those facilities accepting carcasses directly as fallen stock) is therefore estimated as:

$$
\begin{aligned}
I_{\_} \text {drain }_{a, i, k}= & \sum_{t} P_{-} \text {floor }_{a, k}{ }^{*} I_{-} \text {carcass }_{a, i}{ }^{*} \\
& \times\left(1-P_{-} \text {trap }\right),
\end{aligned}
$$

where $k$ is equal to REN and SIN accept entire carcasses $P_{\text {floor }}$ fl, $_{k}$ denotes the percentage of infectivity that falls to the floor (\%). For all other rendering and large and small incinerators nodes (i.e., those accepting parts of carcasses including SRM materials), the amount of infectivity passing through the drains is estimated by the following simplified Equation (4):

$$
\begin{aligned}
I_{-} \text {drain }_{a, i, k}= & \left(P_{-} \text {floor }_{a, k}{ }^{*} I_{-} \text {Cat } 1_{a, i, k}\right) * \\
& \times\left(1-P_{-} \text {trap }\right),
\end{aligned}
$$

where $k$ is equal to RENp, INCp and SINp accept parts of carcasses, and $I_{-}$Cat $1_{a, i, k}$ is the calculated amount of infectivity from one carcass contained in the Category 1 bin transported from those facilities providing input materials as estimated in Equation (2).

\subsection{Infectious Tissues and Infectivity Titres, Infectivity $_{a, i, t}$}

A number of different tissues in cattle infected with BSE have been found to be infectious or positive for prion protein; however, at clinical onset the vast majority of infectivity is present in the brain and spinal cord of the animal. To simplify the assessment, only those tissues in the CNS were included and infected animals were assumed to be at clinical onset-at which point the highest titres of infectivity in the CNS have been measured. The brain and the spinal cord have similar titres of infectivity, ${ }^{(17)} \mathrm{de}-$ fined as Infectivity ${ }_{C, b s e}$ (Bovine Oral ID $_{50}$ per gram). This value was estimated by converting the titre of infectivity expressed as $\log _{10}$ Mouse intercerebral (i.c.) intraperitonial (i.p.) ID $_{50}$ per gram $(\operatorname{MaxCNS})$ by a conversion factor from Mouse units to Bovine Oral units (BOunit):

$$
\text { Infectivity }_{C, \text { bse }}=\frac{10^{\text {MaxCNS }}}{10^{\text {BOunit }}},
$$

where MaxCNS was described using a normal distribution and BOunit was described using a betapert distribution (see Table I).

There are a number of tissues that have been identified as carrying significant levels of classical scrapie infectivity in sheep because the organ and tissue distribution of infectivity is more widespread than for BSE in cattle. The titre of infectivity Infectivity $_{a, s c, t}$ (Ovine Oral $\mathrm{ID}_{50}$ per gram) was estimated by the following equation with values shown in Table I:

$$
\text { Infectivity }_{a, s c, t}=\text { P_infectivity }_{a, s c, t} * \frac{10^{\text {Max }_{s, t}}}{10^{\text {OOunit }}},
$$

where $\operatorname{Max}_{s c, t}$ denotes the maximum titre of infectivity $\left(\log _{10}\right.$ Mouse i.c. ID $_{50}$ per gram) for tissue type $t \in\{1$ to 14$\}$. For tissues $t=1-9$ estimates of infectivity were taken from Kimberlin and Wilesmith, ${ }^{(3)}$ who reanalyze data from Hadlow et al. ${ }^{(18,19)}$ For each infectivity titre, a mean value of the sample data is given (expressed as $\log _{10}$ Mouse i.c. ID $_{50}$ per gram) along with a standard error. The uncertainty about the maximum was described by a normal 
Table II. Estimated Mean Amount of TSE Infectivity from One Carcass to Drain by Facility Type (90\% Confidence Interval in Parentheses)

\begin{tabular}{|c|c|c|c|c|}
\hline \multirow[b]{2}{*}{$\begin{array}{l}\text { Animal Population } \\
\text { and Disease }\end{array}$} & \multicolumn{4}{|c|}{ Mean Amount of Infectivity to Floor Oral $\operatorname{ID}_{50}\left(5^{\text {th }}, 95^{\text {th }}\right.$ Percentiles $)$} \\
\hline & $\begin{array}{l}\text { Abattoir } \\
\text { (AB) }\end{array}$ & $\begin{array}{c}\text { Intermediate/Small } \\
\text { Incinerators (INT/SIN) }\end{array}$ & $\begin{array}{l}\text { Collection Center } \\
(\mathrm{CCN})\end{array}$ & $\begin{array}{c}\text { Renderer/Large } \\
\text { Incinerators (REN/INC) }\end{array}$ \\
\hline BSE in cattle & $2.2(0.1,9)$ & $4.5(0.1,18)$ & $3.6(0.1,14)$ & 7.4(0.1,29) \\
\hline Classical scrapie in sheep & $\begin{array}{c}0.05 \\
\left(8 \times 10^{-3}, 0.1\right)\end{array}$ & $\begin{array}{c}0.51 \\
\left(6 \times 10^{-2}, 1.6\right)\end{array}$ & $\begin{array}{c}0.52 \\
\left(6 \times 10^{-4}, 1.6\right)\end{array}$ & $\begin{array}{c}0.9 \\
(0.1,3)\end{array}$ \\
\hline Classical scrapie in lambs & $\begin{array}{c}3 \times 10^{-3} \\
\left(7 \times 10^{-4}, 9 \times 10^{-3}\right)\end{array}$ & $\begin{array}{c}2 \times 10^{-6} \\
\left(2 \times 10^{-7}, 5 \times 10^{-6}\right)\end{array}$ & $\begin{array}{c}2 \times 10^{-3} \\
\left(3 \times 10^{-4}, 6 \times 10^{-3}\right)\end{array}$ & $\begin{array}{c}0.02 \\
\left(3 \times 10^{-3}, 0.07\right)\end{array}$ \\
\hline Atypical scrapie in sheep & $\begin{array}{c}0.02 \\
\left(2 \times 10^{-3}, 0.1\right)\end{array}$ & $\begin{array}{c}2.1 \\
\left(3 \times 10^{-1}, 6.2\right)\end{array}$ & $\begin{array}{c}0.4 \\
\left(4 \times 10^{-2}, 1.1\right)\end{array}$ & $\begin{array}{c}0.5 \\
(0.05,2)\end{array}$ \\
\hline Atypical scrapie in lambs & $\begin{array}{c}1 \times 10^{-3} \\
\left(2 \times 10^{-4}, 4 \times 10^{-3}\right)\end{array}$ & $\begin{array}{c}2 \times 10^{-6} \\
\left(2 \times 10^{-7}, 5 \times 10^{-6}\right)\end{array}$ & $\begin{array}{c}3 \times 10^{-7} \\
\left(2 \times 10^{-8}, 1 \times 10^{-6}\right)\end{array}$ & $\begin{array}{c}4 \times 10^{-4} \\
\left(4 \times 10^{-5}, 0.001\right)\end{array}$ \\
\hline
\end{tabular}

distribution where the sample mean was used as the mean value and the standard error was used as the standard deviation (Table I). Other tissues have also been found to harbor infection or had abnormal prion protein detected within them. Low levels of infectivity of the stomach, heart, and kidney $(t$ $=10,11$, and 12 ) were described by point values. ${ }^{(4)}$ In the absence of information regarding the infectivity titre of the duodenum and jejunum $(t=13)$, it was assumed that the level of infectivity in these tissues is the same as in the ileum $(t=6)$. This is a worst-case assumption because the ileum is classified as SRM for sheep of all ages whereas the duodenum and jejunum are not. Evidence of classical scrapie infectivity has been detected in the blood of sheep at low titres. ${ }^{(20)}$ This has been modeled as between -1 and $0 \log _{10}$ Mouse i.c. ID $_{50}$ per gram, described using a uniform distribution. Low levels of infectivity have also been observed in the pituitary gland, cerebrospinal fluid, and adrenal gland. ${ }^{(21)}$ These tissues are respectively paired with the brain, spinal cord, and kidney for ease of assessing their weight. Other tissues containing low amounts of infectivity are the PNS, ${ }^{22,23)}$ tongue, ${ }^{(24)}$ bone marrow, and supramammary lymph node. ${ }^{(21)}$ Given that the titre of infectivity in these tissues is considered low, when compared to other infectious tissues that are being considered, these tissues were not quantitatively assessed.

$P_{\text {infectivity }}, s c, t$ refers to the proportion of maximum classical scrapie infectivity present when an animal is slaughtered or dies. The majority of clinical cases of classical scrapie appear in sheep between two years and five years of age. ${ }^{(25)}$ During the progression of the disease, infectivity accumulates in different tissues at different rates. It is also important to note that the vast majority of sheep are slaughtered before the age of seven in the United Kingdom and therefore, in a small proportion of classical scrapie cases, the disease may not be fully developed by the time of slaughter. In this risk assessment, two age groups were considered, lambs under one year old and sheep over one year old. The percentage increase in infectivity at different ages was adjusted accordingly for lambs under one year of age, ${ }^{(5)}$ except for the lymph nodes and intestine (duodenum, jejunum, and ileum) where the percentage of infectivity was estimated as $40 \%$. For sheep over the age of one year, the percentage of infectivity in all tissues was estimated to lie between $70 \%$ and $100 \%$ described by a uniform distribution.

A conversion factor, OOunit, was used to obtain approximations of these titres in units of Ovine Oral ID $_{50}$ per gram. Titres of infection as calculated by intracerebral and intragastric routes of exposure (expressed as sample mean \pm standard error of $\log _{10}$ ID $_{50}$ per $30 \mathrm{mg}$ of mouse brain) are given in Kimberlin and Wilesmith. ${ }^{(3)}$ Using these data, the intracerebral route titre was described by a normal distribution with mean 7.03 and variance 0.0169 , and the intragastric route titre is described by a normal distribution with mean 2.03 and variance 0.0361 . Because the values of these distributions are in units of $\log _{10}$, an estimate for OOunit is obtained by subtracting the intragastric route titre from the intracerebral route titre, which results in a normal distribution with mean 5 and variance 0.053 .

The titre of infectivity (Ovine Oral ID $_{50}$ per gram) for tissues from animals infected with atypical scrapie, Infectivity ${ }_{a, a t, t}$, was estimated by the following equation with values shown in Table I:

$$
\text { Infectivity }_{a, a t, t}=P_{- \text {infectivity }_{a, a t, t}} * \frac{10^{\text {Max }_{a t, t}}}{10^{\text {OOunit }}} \text {. }
$$




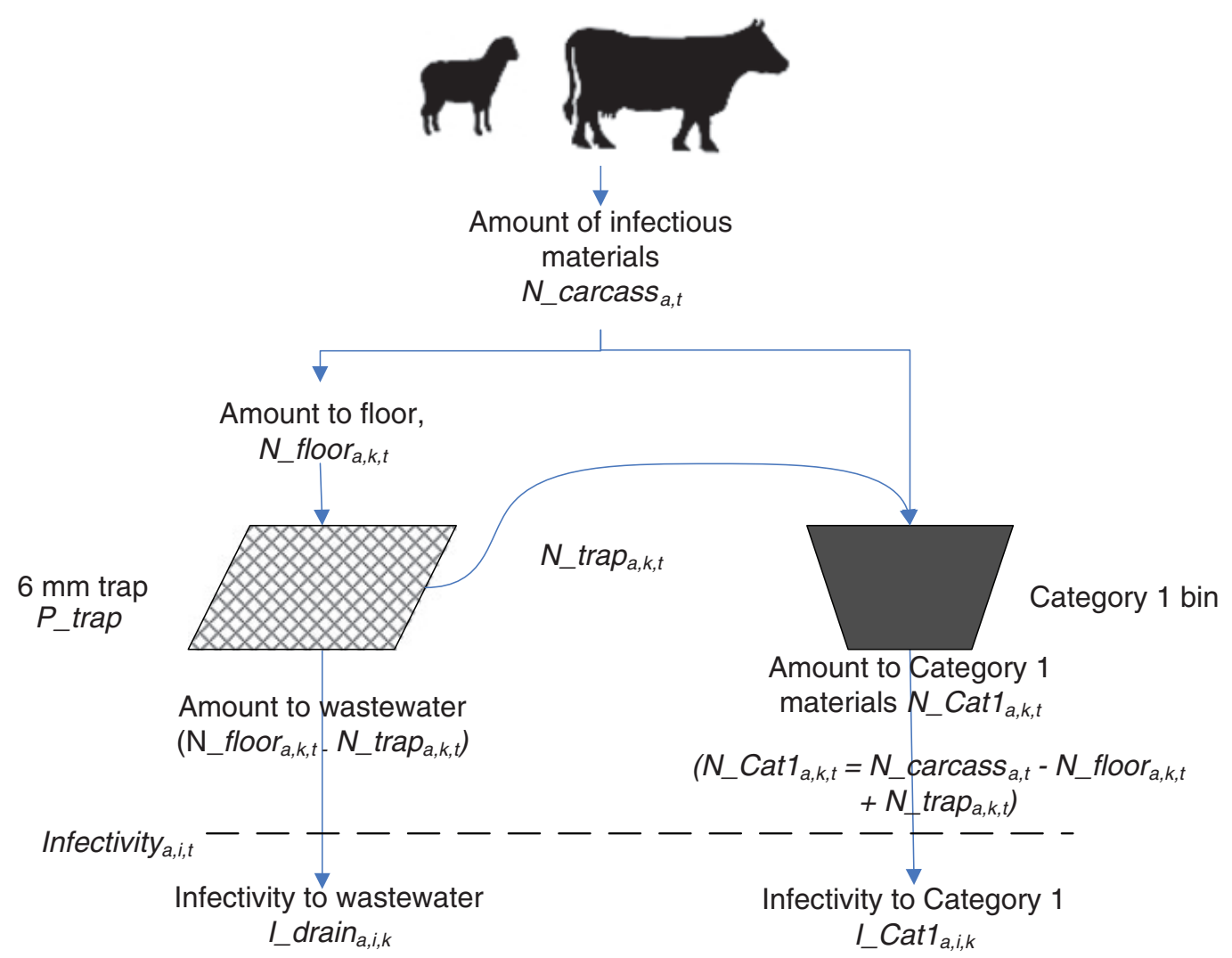

Fig. 1. Flow of material at abattoir, intermediate and collection center to trap and Category 1 bin.

$\operatorname{Max}_{a t, t}$ denotes the maximum titre of infectivity $\left(\log _{10}\right.$ Mouse i.c. ID 50 per gram) by tissue type $t$. The number of potentially infectious tissues for atypical scrapie has been found to be much more restricted than for classical scrapie. Previous studies suggest that infection is limited to the $\mathrm{CNS}^{(26)}$ and lymph nodes. The titre of infectivity is not known although experiments in this area are ongoing. Therefore, for brain and spinal cord, it was assumed that the titre is the same as that measured for the CNS for classical scrapie. If infection is present in the peripheral tissues, then the titre of infectivity was estimated to be between 5 and 6 logs less than in CNS tissues (Simmons, AHVLA, personal communication, 2009). On the basis of only eight clinical cases, the incubation period of atypical scrapie is at least two to three times longer than for classical scrapie (Simmons, AHVLA, personal communication, 2009). Hence the distribution of infectivity with age for CNS tissues and lymph nodes estimated for classical scrapie was adjusted accordingly: for lambs under one year old the percentages for the brain,
$P_{-}$infectivity $_{l, a t, 1}$, and spinal cord, P_infectivity ${ }_{l, a t, 2}$, are $0.1 \%$. For the lymph nodes, the percentage of infectivity, P_infectivity l,at, $3_{3}$, is lowered to $0.1 \%$ as there is no evidence to suggest that the progression of the disease is faster in these tissues than in the CNS. For sheep over the age of one year, the percentage of infectivity in all of the tissues at the time of slaughter, P_infectivity ${ }_{S, a t, t}$, is estimated to lie between $40 \%$ and $80 \%$.

\subsection{Material Flow at Abattoir, $N_{-}$carcase $_{a, t}$, and $N_{f}$ lloor $_{a, A B, t}$}

There are two drain areas at abattoirs $(k=$ $A B)$; one floor area includes the processing stages of stunning, head removal, and bleeding and, if required, CNS sampling for TSE testing, and flows into the blood tank, which is disposed of as Category 1. Wash down from the floor areas for processing the remainder of the carcass will flow via the trap into wastewater.

A large number of studies have investigated the release of BSE infectivity or markers of infectivity 
during abattoir processing, to the food chain and Category 3 material (summarized in Refs. 27 and 28 ) and to the floor ${ }^{(29-31)}$ with a key project undertaken by the French Food Safety Agency (AFSSA). AFSSA conducted an experiment to determine the amount of CNS going to the floor using glial fibrillary acidic protein (GFAP) detection, as it is specifically expressed in the CNS. An estimated total of $2.73 \mathrm{~g}$ of CNS material from each carcass flowed to the trap including that from the blood bath areas. (10) In this risk assessment the content of the blood tank is correctly disposed of as Category 1 material and therefore the only contribution to infectious material on the floor per carcass is a mean of $1.03 \mathrm{~g}$ from the handling of head meat contaminated by brain, $N_{\text {floor }}, A B, 1$, assumed to be the same as that transferred to head meat, ${ }^{(32)}$ and $0.27 \mathrm{~g}$ of contamination from the spinal cord following splitting of the carcass, $N_{-}$floor $_{C, A B, 2} \cdot{ }^{(10)}$ There is uncertainty in these estimates, which was described by a betapert distribution fitted to the mean $(1.03 \mathrm{~g})$ and percentiles $(0.18,2.69)$. The total amount of infectious CNS tissue for cattle is composed of tissues within the skull (brain $500 \mathrm{~g}$, retina $1 \mathrm{~g}$, trigeminal ganglia $20 \mathrm{~g}^{(6)}$ ), and spinal cord (between $200 \mathrm{~g}$ and $\left.482 \mathrm{~g}^{(6,33)}\right)$. These weights for infectious cattle tissues, $N_{-} \operatorname{carcass}_{C, t}$, were used for the abattoir, intermediate plant, and collection center facilities and those renderers and incinerators accepting whole animals.

The amount of material falling to the floor and placed in Category 1 bins at abattoirs was separately estimated for sheep and lambs. Tissue weights and associated references are presented in Table I. Blood lost at exsanguination is disposed of as Category 1 material through use of a blood tank. It is estimated that $40-60 \%{ }^{(11)}$ of the total blood volume of a sheep $(2,720 \mathrm{~g})$ is collected here. The amount of blood loss due to further processing, $N_{-}$floor $_{S, A B, 14}$, was assumed to fall to the floor and estimated to be 10-20\% of the original blood content (272-544 g). The tonsils $(3.2 \mathrm{~g})$ and the skull including brain (160 g) and eyes are classified as SRM for sheep over one year old and are disposed of as Category 1 material. In this risk assessment all other tissues classified as SRM, namely, the spinal cord (50-64 g), ileum (200 g), and spleen $(300 \mathrm{~g})$, removed as part of evisceration, contaminate the floor during removal. The amount of spinal cord material going to the floor, $N_{f}$ floor $_{S, A B, 2}$, was estimated to be the same proportion by weight as the amount of spinal cord that is lost to the floor for cattle, estimated by the following equation where $t$ is equal to 2 , spinal cord:

$$
N_{-} \text {floor }_{S, A B, 2}=\left(\frac{N_{-} \text {floor }_{C, A B, 2}}{N_{-} \operatorname{carcas}_{C, 2}}\right) * N_{-} \text {carcass }_{S, 2} \text {. }
$$

For the spleen and ileum it was estimated that between $0.01 \%$ and $0.1 \%$ of these tissues go to the floor (assessors, assumption based on observation, 2009). It was estimated that all other infectious tissues and blood remaining in the carcass either enter the food chain or are disposed of as Category 3 materials.

The amount of material going to the floor and Category 1 bin at abattoirs for lambs differs from sheep. This is due to different SRM controls being in place for sheep under one year old and lamb tissues weighing less than sheep (lamb tissue weights and references are given in Table I). At exsanguination it was estimated that $40-60 \%$ of the total amount of blood in a lamb $(1,700 \mathrm{~g})$ is disposed of as Category 1 material using a blood tank, $N_{-}$carcass $_{l, 14}{ }^{(11)}$ The amount of blood falling to floor, $N_{-}$floor $_{l, A B, 14}$, was estimated to be between $170 \mathrm{~g}$ and $340 \mathrm{~g}$ (10$20 \%$ of the original blood content). Unlike sheep aged over one year the tonsils and skull including brain and eyes are not classified as SRM and can be disposed of as Category 2 material. However, most abattoirs dispose of the head as Category 1 material in order to reduce cost. Infectious tissues associated with the head are the brain $(100 \mathrm{~g})$ and tonsils $(2 \mathrm{~g})$. It was estimated that the amount of brain material that is lost to the floor due to handling of the head, $N_{\text {f }}$ floor $_{l, A B, 1}$, is between $1 \mathrm{~g}$ and $2 \mathrm{~g}$ (i.e., $1-2 \%$ of all brain material). The tonsils and the remaining brain material are disposed of as Category 1 waste. The spleen $(75 \mathrm{~g})$ and the ileum (100 g), which are SRM for sheep of all ages, were assumed to be removed at evisceration with the same proportions going to floor as for sheep. All remaining tissues and blood in the carcass enter the food chain or Category 3 materials.

\subsection{Material Flow at Intermediate Plants, $N_{\text {floor }}, I N T, t$}

Intermediate plants $(k=I N T)$ carry out the collection of fallen stock from farms and, where a valid license is held, carry out testing for TSEs. Testing for TSEs involves the removal or partial removal of the head from the carcass. There is usually no blood tank prior to collection of wastewater. On the basis of a visit made to such a facility, three key routes have been identified by which CNS tissues may 
contaminate the floor and subsequently wastewater: (Route 1) when the carcass is hoisted brain fragments leak from the hole in the skull made by the captive bolt; (Route 2) from shot animals brain fragments lost in blood from the head/neck due to decomposition or emboli; and (Route 3) brain material released to the floor during sampling for the TSE test. The estimated amounts of infectious material (in grams) of a carcass going to the floor and subsequently to trap from each of these three routes are given in Table I. All material retained by the trap is disposed of as Category 1 waste.

For Route 1, the probability of adult livestock being shot dead on farm has been estimated and represented in the model by a range of $60-85 \%$ of fallen stock entering intermediate facilities (discussions with intermediate facility managers, 2009). The majority of fallen lambs are born dead or die naturally shortly after birth. The estimated probability of lambs being assisted is between $0.1 \%$ and $1 \%$, of which an estimated $10 \%$ are shot (Animal Health Veterinary Officers, personal communication, 2009). AFSSA investigated the amount of CNS material falling to the floor during captive bolt stunning of cattle. Fifteen percent of animals stunned lost brain fragments of an average weight of $0.34 \mathrm{~g} .{ }^{(10)}$ In the absence of data for the frequency of use of captive bolts, or in rare cases rifles, to put down animals on farm, it was assumed that between $0.34 \mathrm{~g}$ and $1 \mathrm{~g}$ of material may be lost from gunshot wounds during movement of the carcass in the yard area.

For Route 2 approximately half of all animals at an intermediate plant had some bleed out, either due to being freshly slaughtered or, particularly in the summer months, due to significant decomposition (discussions with intermediate facility managers, 2009). This was represented in the model as a range between $40 \%$ and $60 \%$ using a uniform distribution. For cattle the amount of brain material lost during these bleeds is the same as that estimated for emboli caused by stunning, that is, between 1 and 10 g. ${ }^{(12)}$ For sheep and lambs, it was estimated that the same proportion of total brain weight is lost during these bleeds.

The AFSSA study measured an average of 0.568 $\mathrm{g}$ of brain lost during testing for BSE in cattle (range of $0.01-1 \mathrm{~g}$ ), which was represented in the model using a betapert distribution. ${ }^{(10)}$ To simplify the assessment, all cattle lose brain material at intermediate plants in the risk assessment, whereas at the current time only those cattle older than 48 months are tested. For sheep the same proportion of total brain weight is lost during testing, with the proportion of sheep subjected to an obex test estimated as $9,300^{(13)}$ divided by the total number of sheep in the fallen stock stream estimated as approximately 280,000 . It is important to note that in contrast to sheep and cattle, lambs are not tested for TSEs. For sheep and lambs it was estimated that all other infectious tissues remain inside the carcass.

\subsection{Material Flow at Collection Centers, $N_{-}$floor $_{a, C C N, t}$}

Collection centers $(k=C C N)$ do not test for TSEs but are licensed to remove flesh (Category 2) for dogs (kennels) and zoo animals from animals that are certified not to contain any medication residues and have not been TSE tested. During processing, livestock have their heads removed and carcass eviscerated with the entire head and guts placed in the Category 1 bin. Meat from the legs is removed, and back meat and ribs removed by sawing and cutting. The vertebral column is not split and is placed in Category 1 waste with the remaining skeleton. Normally, there is no blood tank before collection of wastewater. From a visit conducted at this type of facility two important routes were identified in which CNS tissues may contaminate the floor and subsequently wastewater: (Route 1) brain fragments exiting the gunshot wounds when the head is removed/handled from those animals shot in the head; and (Route 2) brain fragments lost in blood from shot animals from the head/neck due to decomposition or emboli when the carcass is handled for flesh removal.

It was assumed that the amount of infectious material going to the floor for Routes 1 and 2 following the handling of carcasses at collection centers is the same as that estimated for intermediate plants. It is important to note that for sheep and lambs, the ileum may be removed and is disposed of as Category 1 waste. During this process it was estimated that a proportion of the ileum is lost to the floor. In the model the amount of the ileum material going to the floor, $N_{-}$floor $_{S, C C N, 6}$ and $N_{\text {floor }}$ flCCN, $_{,}$, is the same as for sheep and lambs at abattoir (i.e., between $0.02 \mathrm{~g}$ and $0.2 \mathrm{~g}$ ). All remaining infectivity enters Category 1 waste.

\subsection{Material Flow at Rendering Facilities, Pffloor $_{a, R E N, t}$}

The principal route of infectious material going to the floor at rendering facilities $(k=R E N)$ comes 
from TSE sampling and the crusher within the carcass receipt shed (Animal Health Veterinary Officers, personal communication, 2009). Carcasses enter the yard and are crushed and the minced material pumped to the raw material hoppers. TSE sampling may produce small amounts of material going to the floor and the crusher interior cleaning operation results in most of the solids being removed manually rather than washed down the drain. The proportion of infectivity falling to the floor, $P_{-}$floor $_{a, i, R E N}$, for $a$ $\in\{C, S, l\}$ and $i \in\{b s e, s c, a t\}$, was described in the model using a betapert distribution with a most likely value of 0.003725 , a minimum of 0.0001 , and a maximum of $0.015 .^{(14,15)}$

\subsection{Material Flow at Incinerator Facilities, $\boldsymbol{P}_{\text {floor }},{ }_{, S I N, t}$, and $\boldsymbol{P}_{\text {ffloor }}$, INC,$t$}

The majority of incinerators in GB is relatively small in scale and owned by groups incinerating a range of waste materials (Animal Health Veterinary Officers, personal communication, 2009). These include crematoria that also handle pets, intermediate plants and collection centers, and veterinary center incinerators. From a survey of lead Veterinary Officers, only 10-12 operational high throughput incinerators were identified in GB that are licensed to process Category 1 materials and fallen stock. Processing controls at small incineration plants (SINs) are significantly different than at large industrial incinerators and technical facilities (INCs). Therefore, small and large incineration facilities were considered separately in the assessment.

The proportion of infectivity falling to the floor at small incinerators $(k=S I N)$ is dependent on the type of material that is being processed. For fallen stock arriving from farms, the proportion of infectivity falling to the floor, $P_{-}$floor $_{a, S I N, 1}$, was assumed to be the same as the proportion of infectivity from a single carcass going to trap at an intermediate plant. For materials transported from intermediate plants and collection centers, the proportion of infectivity per carcass falling to floor, $P_{-}$floor $_{a, S I N, 2}$, was estimated to be the same as that estimated for a collection center. For high throughput incinerators and technical plants $(k=I N C)$, which process SRM from abattoirs and MBM from rendering facilities, the proportion of infectivity to floor, $P_{-}$floor $_{a, I N C}$, is estimated to be the same as that estimated for a rendering facility.

\subsection{Proportion of Infectivity Retained by Trap, P_trap}

It is a legal requirement for SRM handling facilities to have a 6-mm trap, with any sludge retained classified as Category 1 material. ${ }^{(34)}$ Research conducted by AFSSA attempted to measure the amount of CNS material that was retained at abattoir and the proportion that flowed through the trap. ${ }^{(10)}$ However, the experimental protocol used did not enable quantitative estimates. The proportion of material that is retained by the trap, P_trap, is based on those estimates available in the literature, between 0.8 and 0.9. ${ }^{(10,14)}$

A key assumption in this risk assessment is that there is no illegal activity of lifting the drain and allowing the material retained to pass into wastewater. However, the efficiency of the trap is further explored by scenario analysis (refer to Section 3). In addition, we have considered only a 6-mm trap. Many facilities use a 4-mm, 2-mm, or even a 1-mm trap to retain material and therefore improve the quality of resulting wastewater. However, the numbers of plants that use more selective traps is not known and may vary between facility types.

\section{RESULTS}

Uncertainty is considered in the model and represented by 5 th and 95 th percentiles (within parentheses), which indicate the range within which $90 \%$ of the results lie. The model was run for 200,000 iterations using Latin Hypercube sampling. It should be emphasized that not all uncertainty has been estimated in the calculations, as not all can be quantified. Therefore, the 5th and 95th percentiles describe the amount of quantified uncertainty included in the model.

\subsection{Amount of Infectivity in a Whole Carcase, $I_{-}$carcase $_{a, i}$}

For cattle infected with BSE the mean amount of infectivity was estimated to be 9864 Bovine Oral (BO) ID $_{50}$ per carcass $(310,38840)$. This estimate is based on infectious CNS tissue for an animal at maximal infectivity, that is, clinical onset, and therefore worst case. The distribution is highly positively skewed with a mode of $365 \mathrm{BO} \mathrm{ID}_{50}$ per carcass. For adult sheep the amount of infectivity for classical scrapie, 1851 Ovine Oral (OO) ID 50 per carcass $(600,4070)$, is on average, over threefold higher than 
estimated for atypical scrapie (614 OO ID 50 per carcass $(155,1509))$. When considering scrapie infected lambs, infectivity is significantly lower than for adults with 251 OO ID $_{50}$ per carcass $(83,548)$ for classical scrapie and 1 OO ID I0 $_{50}$ percass $(0.2,2)$ for atypical scrapie.

\subsection{Amount of Infectivity to Drain by Facility Type, I_drain $a, i, k$}

The estimated amounts of infectivity falling to the floor and through the trap as a result of processing carcasses are displayed in Table II. The highest amounts of infectivity entering drains from a whole carcass at SRM facilities were found to be from BSE in cattle at rendering and large incineration facilities with a mean of $7.4 \mathrm{BO}^{-D_{50}} \mathrm{~s}(0.1,29)$, intermediate plants and small incinerators with a mean of 4.5 BO ID ID $_{50}(0.1,18)$, and collection centers, $3.6 \mathrm{BO}$ $\mathrm{ID}_{50} \mathrm{~s}(0.1,14)$. The lowest amounts entering drains are from lambs infected with classical and atypical scrapie at intermediate plants and atypical scrapie at collection centers with a mean of $3 \times 10^{-7}$ OO $\mathrm{ID}_{50} \mathrm{~S}$ $\left(2 \times 10^{-8}, 1 \times 10^{-6}\right)$ per carcass.

\subsection{Sensitivity Analysis}

A multivariate stepwise regression analysis was used to calculate linear regression or sensitivity values for each value represented by a probability distribution. This method is preferred for large numbers of input parameters, as all values that provide an insignificant contribution are removed from the analysis. All parameters described by a range were included in the sensitivity analysis. Sensitivity values were estimated for the total amount of TSE infectivity in a whole carcass and the amount going to floor at SRM handling facilities. For BSE in cattle, the results were strongly affected by two parameters: (1) uncertainty associated with the infectivity titre in the CNS at clinical onset, MaxCNS, and (2) uncertainty associated with the conversion of Mouse i.c. i.p. units to Bovine Oral units, BOunit. Other parameters affecting the results were the amount of brain contamination from head meat removal at an abattoir, $N_{-}$floor $_{C, A B, 1}$, the weight of blood containing brain fragments leaking to floor at intermediate plants and collection centers, and the proportion of infectious material going to floor at a rendering facility, $P$-floor, bse,$R E N$.

For classical and atypical scrapie in sheep and lambs, the results were all strongly affected by the uncertainty associated with the titre conversion factor, OOunit. Other parameters affecting the results were (1) maximum titre of classical scrapie infectivity in the brain, spinal cord, and ileum ( $\operatorname{Max}_{s c, 1}, \operatorname{Max}_{s c, 2}$, $\left.\operatorname{Max}_{s c, 6}\right)$, (2) proportion of ileum going to floor during removal at abattoirs and collection centers, (3) proportion of fallen lambs that have been shot by a pistol or rifle, (4) weight of brain material going to floor at intermediate plants and collection centers due to gunshot wounds, and the (5) proportion of infectious material going to floor at a rendering facility, $P_{\text {floor }}, i, R E N$.

\section{DISCUSSION}

Central to risk assessments investigating the animal health risk associated with the application of effluents from carcass processing facilities is the estimation of the amount of infectivity entering the process, the remainder that survives any processing, and the proportion applied to land where livestock have access. This risk assessment provides a comprehensive framework for the first step in this process: the estimation of the amount of TSE diverted to wastewater during processing per infected carcass. Subsequent stages are described and assessed in the second paper in the series titled "A Quantitative Assessment of the Prion Risk Associated with Wastewater from Carcass Handling Facilities."

Although a number of researchers have considered the risks posed by cattle BSE at abattoir, there has been limited previous work at other plants processing high risk Category 1 carcass materials and no prior assessments investigating the quantitative risk posed by classical and atypical scrapie from these locations. Our results suggest that the highest amounts of infectivity falling to the floor and entering the drains from slaughtering a whole carcass at SRM facilities were found to be at rendering and large incineration facilities for each pathogen and age group except atypical scrapie in lambs where inputs to abattoir effluent were highest.

Atypical scrapie has been included as a hazard but little is known about sources of infection and epidemiology. Recent studies have not found any risk factors associated with an infectious origin suggesting that atypical scrapie in sheep is a spontaneous disease. ${ }^{(35)}$ However, oral transmission of atypical scrapie has been recently experimentally demonstrated ${ }^{(36)}$ suggesting this prion disease could be transmitted by environmental pathways such as contaminated wastewater. 
Table III. Comparison of Mean Values Used in This Risk Assessment (Minimums and Maximums Provided in Parentheses) with Other Estimates Available in the Literature

\begin{tabular}{lccc}
\hline Facility Type & Percentage of Infectivity to Floor & Weight of Infectivity to Floor & Estimates Available in the Literature \\
\hline Abattoir (AB) & $0.15 \%(0.04,0.6)$ & $1.3 \mathrm{~g}(0.41,4.6)$ & $2.73 \mathrm{~g}^{*}$ (AFSSA, 2003) \\
& & $1-20 \mathrm{~g}(\mathrm{BRS}, 2001)$ \\
& & - & $0.01-1 \%(\mathrm{Gale}$ and Stanfield, 2001) \\
Collection center (CCN) & $0.24 \%(0.03,0.7)$ & - & $0.7 \%(\mathrm{DNV}, 1997 \mathrm{a})$ \\
Renderer (REN) & $0.37 \%(0.01,1.5)$ & - & $0.5 \%(\mathrm{DNV}, 1997 \mathrm{a})$ \\
Large incinerator (INC) & $0.37 \%(0.01,1.5)$ & $0.011 \%(\mathrm{DNV}, 1997 \mathrm{a})$ \\
\hline
\end{tabular}

*Includes blood bath.

The approach taken in this risk assessment for modeling abattoirs, intermediate plants, and collection centers was mechanistic, that is, each infectious tissue was considered at each stage in the processing of carcasses for the potential of falling to floor. Other risk assessments ${ }^{(14,37)}$ have been more heuristic, estimating an overall fraction of the carcass infectivity falling to floor. This approach was used to model rendering and incineration plants in the current risk assessment. Table III provides a comparison of values used in this risk assessment as compared to those used in previous risk assessments. There are two different units; first, the mean percentage of infectivity to floor (\%) based on total infectivity per carcass, and second the equivalent weight of infectious tissue to floor (g). From the table it can be seen that the values previously used in analyses are within the range used in this risk assessment with some exceptions. The Australian abattoir model used an upper limit of $20 \mathrm{~g} \mathrm{CNS}$ tissue per carcass. ${ }^{(38)}$ This may be due to different abattoir practices in place in Australia when compared to Europe. In addition, the upper estimate for abattoirs in Gale and Stanfield ${ }^{(37)}$ is outside our maximum range. This is likely to reflect the change in abattoir controls brought about by the ABP regulations in 2002. ${ }^{(34)}$ For the AFSSA study the total 2.73 $\mathrm{g}$ of infectious material to the floor includes $0.82 \mathrm{~g}$ collected in the area of the blood bath that is collected separately at abattoir for Category 1 disposal under the ABP regulations. Of the remaining material $0.27 \mathrm{~g}$ is assumed to arise from carcass splitting and $1.64 \mathrm{~g}$ arising from "drain vats." ${ }^{(10)}$ Contact with several of the AFSSA reports authors has not further elucidated the origin of this infectivity.

The mechanistic approach taken here required quantitative data for each parameter, and for this risk assessment, many of these parameters are not well known. Industry managers, government officials involved in monitoring facilities, industry association representatives, and disease specialists were con- tacted to elicit expert opinion for the stratifications included: various infectious tissue types, pathogens, animal populations across six different facility types. Where data were still absent, several observational visits were conducted to view the slaughtering and testing procedures at each of the facility types to produce the assessors' opinion. Upon completion of the risk assessment, stakeholders met together to discuss and agree on ranges of values used in the risk assessment and areas of data uncertainty.

From the sensitivity analysis the parameters with the greatest impact on the results are the uncertainty associated with disease characteristics of tissue infectivity and $\mathrm{ID}_{50}$ conversion units (MaxCNS, BOunit, OOunit), which have been found to significantly impact other TSE risk assessments. ${ }^{(27)}$ In view of the steady decline of BSE risk to public health, it would seem unlikely that any further large animal TSE disease research, particularly BSE, giving rise to quantitative data appropriate for the risk assessment will be funded. Therefore, it would be difficult to reduce this uncertainty further. However, when considering the overall result, for example, the estimated amount of infectivity to drains from cattle at rendering plants, the upper $90 \%$ uncertainty bounds are not much greater than the mean, where the mean is 7.4 BO $I_{50}$ s, while the upper 90th percentile increases to $29 \mathrm{BO} \mathrm{ID}_{50} \mathrm{~s}$. Therefore, the funding of further research from this risk assessment is unlikely to be recommended from these results.

For the risk assessment presented here one of the major reasons for adopting a mechanistic approach was the need for comparisons-comparing across different TSE pathogens and different carcass handling facility types. Such comparisons would be extremely difficult to make heuristically due to the multidisciplinary aspects of the risk question. The approach taken permits the discrimination between pathogens and facility type and in our second paper these results are used as input parameters to evaluate 
the overall risk posed by the wastewater arising from these facilities.

\section{ACKNOWLEDGMENTS}

This risk assessment has been funded by the Department of Environment, Food and Rural Affairs (Defra). We express our gratitude for the numerous data providers identified in Table I, particularly the assistance of Dr. Mark Arnold and Dr. Angel Ortiz-Pelaez in their assistance with BSE and scrapie prevalence estimates.

\section{REFERENCES}

1. Wells GH, Konold T, Arnold ME, Austin AR, Hawkins SAC, Stack M, Simmons MM, Lee Y-H, Gavier-Widen D, Dawson M, Wilesmith JW. Bovine spongiform encephalopathy: The effect of oral exposure dose on attack rate and incubation period in cattle. Journal of General Virology, 2007; 88:13631373.

2. Arnold ME, Hawkins SAC, Green RB, Dexter I, Wells GAH. Pathogenesis of experimental bovine spongiform encephalopathy (BSE): Estimation of tissue infectivity according to incubation period. Veterinary Research, 2009; 40:8.

3. Kimberlin RH, Wilesmith JW. Bovine spongiform encephalopathy. Epidemiology, low dose exposure and risks. Annals of the New York Academy of Sciences, 1994; 724:210 220.

4. Gale P. Risk Assessment: Use of Composting and Biogas Treatment to Dispose of Catering Waste Containing Meat. Report to Department for Environment, Food and Rural Affairs. Buckinghamshire: WRc-NSF Ltd, SL7 2HD. Ref. 128420, May 2002.

5. Det Norske Veritas. Risk of Exposure to BSE Infectivity in UK Sheep. Report for the Food Standards Agency. London: Det Norske Veritas Ltd., SE19DE. Report C100110, June 2002.

6. Hart RJ, Church PN, Kempster AJ, Matthews KR. Audit of bovine and ovine slaughter and by-products sector (ruminant products audit). Carried out by Leatherhead Food and Research Association in conjunction with the Meat and Livestock Commission, MAFF, 1997.

7. Spongiform Encephalopathy Advisory Committee. Specified Bovine Materials-The Weighing of Spinal Cords, Spongiform Encephalopathy Advisory Committee Paper No. 39/3, 1996.

8. Fryer HR, Baylis M, Kumar S, McLean AR. Quantifying the risk from ovine BSE and the impact of control strategies. Proceedings of the Royal Society B, 2007; 274(1617):1497-1503.

9. Department of Agriculture and Rural Development. VPHU Manual for Official Controls, Chapter 2.7: Specified Risk Material, 2009. Available at: http://www.dardni.gov.uk/ vphu-moc-chapter-02-7-specified-risk-material.pdf, Accessed January 2011. Available at: http://www.ladocumentationfrancaise.fr/var/storage/rapports-publics/054000086/0000.pdf, Accessed January 2011.

10. Saunier R. Risques sanitaires au regard de l'ESB liés aux rejets dans l'environnement des effluents et boues issus d'abattoirs et d'équarrissages. Agence Francaise de Securite Sanitaire des Aliments, France, September 2003.

11. Warriss PD. Meat Science: An Introductory Text, 1st ed. Wallingford, UK: Cabi Publishing. 2000.

12. Comer PJ, Huntly PJ. Exposure of the human population to BSE infectivity over the course of the BSE epidemic in Great
Britain and the impact of changes to the over thirty month rule. Journal of Risk Research, 2004; 7(5):523-543.

13. Veterinary Laboratories Agency. Scrapie Test Database. Query for Number of Sheep Tested for Scrapie in 2009. Available at: http://vla.defra.gov.uk/science/sci tse.htm, Accessed March 2010.

14. Det Norske Veritas. Overview of Risks from BSE via Environmental Pathways for the Environment Agency. Report for the Environment Agency. Bristol, London: Det Norske Veritas Ltd., SE19DE. C7243, June 1997.

15. Det Norske Veritas. Thruxted Mill Rendering Plant-Risk Assessment of Wastewater Disposal Options. London: Det Norske Veritas Ltd., SE19DE. Ref C7175, January 1997.

16. Det Norske Veritas. Risk Assessment of SRM Incinerators. Prepared for the UK Ministry of Agriculture, Fisheries and Food. London: Det Norske Veritas Ltd., SE19DE. Ref 1000089, March 2001.

17. Arnold ME, Ryan JBM, Konold T, Simmons MM, Spencer YI, Wear A, Chaplin M, Stack M, Czub S, Mueller R, Webb PR, Davis A, Spiropoulos J, Holdaway J, Hawkins SAC, Austin AR, Wells GAH. Estimating the temporal relationship between PrPSc detection and incubation period in experimental bovine spongiform encephalopathy of cattle. Journal of General Virology, 2007; 88:3198-3208.

18. Hadlow WJ, Kennedy RC, Race RE, Eklund CM. Virologic and neurohistologic findings in dairy goats affected with natural scrapie. Veterinary Pathology, 1980; 17(2):187-199.

19. Hadlow WJ, Kennedy RC, Race RE. Natural infection of Suffolk sheep with scrapie virus. Journal of Infectious Diseases, 1982; 146(5):657-664.

20. Terry LA, Howells L, Hawthorn J, Edwards JC, Moore SJ, Bellworthy SJ, Simmons H, Lizano S, Estey L, Leathers V, Everest SJ. Detection of PrPsc in blood from sheep infected with scrapie and bovine spongiform encephalopathy. Journal of Virology, 2009; 83(23):12552-12558.

21. Detwiler LA, Jenny AL, Rubenstein R, Wineland NE. Scrapie: A review. Sheep and Goat Research Journal, 1996; 12(3):111-131.

22. Groschup MH, Weiland F, Straub OC, Pfaff E. Detection of scrapie agent in the peripheral nervous system of a diseased sheep. Neurobiology of Disease, 1996; 3(3):191-195.

23. Groschup MH, Beekes M, McBride PA, Hardt M, Hainfellner JA, Budka H. Deposition of disease-associated prion protein involves the peripheral nervous system in experimental scrapie. Acta Neuropathologica, 1999; 98(5):453457.

24. Casalone C, Corona C, Crescio MI, Martucci F, Mazza M, Ru G, Bozzetta E, Acutis PL, Caramelli, M. Pathological prion protein in the tongues of sheep infected with naturally occurring scrapie. Journal of Virology, 2005; 79(9):5847-5849.

25. World Animal Health Organisation. OIE Terrestrial Manual, 2009; Chapter 2.7.13 Scrapie. Available at: http://www.oie.int/ fileadmin/Home/eng/Health standards/tahm/2.07.13 SCRAPIE.pdf, Accessed January 2011.

26. Benestad SL, Arsac JN, Goldmann W, Noremark M. Atypical/Nor98 scrapie: Properties of agent, genetics, and epidemiology. Veterinary Research, 2008; 39(4):19.

27. Adkin A, Nicholls V, Arnold M, Wells G, Matthews D. Estimating the impact on the food chain of changing bovine spongiform encephalopathy (BSE) control measures: The BSE Control Model. Preventive Veterinary Medicine, 2010; 93(2-3):170-182.

28. Cummins E, Adkin A. Exposure assessment of TSEs from the landspreading of meat and bone meal. Risk Analysis, 2007; 27(5):1179-1202.

29. Prendergast DM, Sheridan JJ, Daly DJ, McDowell DA, Blair IS. Dissemination of central nervous system tissue from the brain and spinal cord of cattle after captive bolt stunning and carcass splitting. Meat Science, 2003; 65(4):1201-1209. 
30. Prendergast DM, Sheridan JJ, Daly DJ, McDowell DA, Blair IS. Dissemination of central nervous system tissue during the slaughter of cattle in three Irish abattoirs. Veterinary Record, 2004; 154(1):21-24.

31. Daly DJ, Prendergast DM, Sheridan JJ, Blair IS, McDowell DA. Use of a marker organism to model the spread of central nervous system tissue in cattle and the abattoir environment during commercial stunning and carcass dressing. Applied and Environmental Microbiology, 2002; 68(2):791-798.

32. Cooper JD, Bird SM. UK dietary exposure to BSE in head meat: By birth cohort and gender. Journal of Cancer Epidemiology and Prevention, 2002; 7(2):71-83.

33. Spongiform Encephalopathy Advisory Committee. Specified Bovine Materials-The Weighing of Spinal Cords. Spongiform Encephalopathy Advisory Committee Paper No. 39/3. 1996.

34. European Commission. Regulation (EC) 1774/2002 of the European parliament and the council laying down health rules concerning animal by-products not intended for human consumption. Official Journal of the European Communities, 2002; L273:0001-0095.

35. Fediaevsky A, Morignat E, Ducrot C, Calavas D. A casecontrol study on the origin of atypical scrapie in sheep, France. Emerging Infectious Diseases, 2009; 15(5):710-718.

36. Simmons MM, Moore SJ, Konold T, Thurston L, Terry LA, Thorne L, Lockey R, Vickery C, Hawkins SAC, Chaplin MJ, Spiropoulos J. Experimental oral transmission of atypical scrapie to sheep. Emerging Infectious Diseases, 2011; 17(5):848-854.

37. Gale P, Stanfield G. Towards a quantitative risk assessment for BSE in sewage sludge. Journal of Applied Microbiology, 2001; 91(3):563-569.

38. Quinn DT, Fabiansson SU. Risk Assessment of Abattoir Effluent Should BSE be Found in Cattle in Australia. A Report Prepared for the NHMRC Special Expert Committee on TSEs. Bureau of Rural Sciences. Kingston, June 2001. 